\title{
Food\& Function
}

\section{Antioxidant, ACE-inhibitory and antimicrobial activity of fermented goat milk: activity and physicochemical properties relationship of the peptide components}

\begin{tabular}{|r|l|}
\hline Journal: & Food \& Function \\
\hline Manuscript ID & FO-ART-05-2017-000666.R1 \\
\hline Datticle Type: & Paper \\
\hline Complete List of Authors: & $\begin{array}{l}\text { Montoro, Miriam; Universidad de Granada Facultad de Farmacia } \\
\text { Olalla, M; Universidad de Granada Facultad de Farmacia } \\
\text { Rufian-Henares, J.A.; University of Granada, Nutrition \& Food Sciences } \\
\text { Gimenez Martinez, Rafael; Universidad de Granada Facultad de Farmacia } \\
\text { Miralles, Beatriz; Instituto de Investigacion en Ciencias de la Alimentacion } \\
\text { Bergillos, Triana; Instituto de Investigacion en Ciencias de la Alimentacion } \\
\text { Navarro-Alarcon, M; University of Granada, Nutrition nad Food Science } \\
\text { Jauregi, Paula ; The University of Reading, }\end{array}$ \\
\hline
\end{tabular}




\section{Food \& Function}

2015 Impact Factor: 2.676

www.rsc.org/foodfunction

\section{FULL PAPER SUBMISSION}

\section{Linking the chemistry \& physics of food with health \& nutrition}

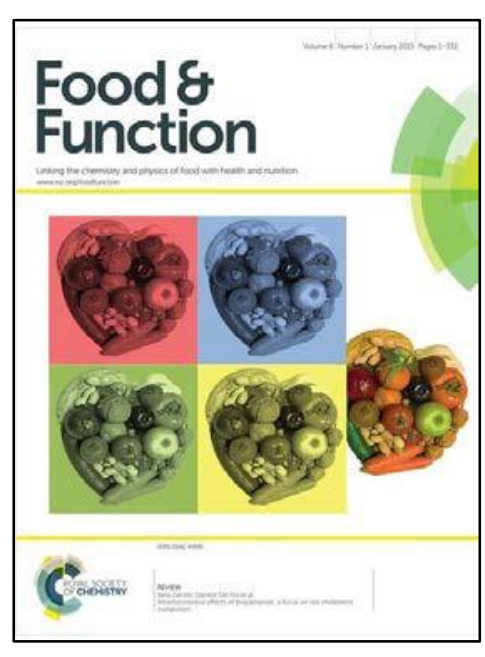

The following article has been submitted to Food \& Function for consideration as a Full Paper.

Food \& Function provides a unique venue for physicists, chemists, biochemists, nutritionists and other food scientists to publish work at the interface of the chemistry, physics and biology of food. The journal focuses on food and the functions of food in relation to health; this includes the following:

- Physical properties and structure of food

- Chemistry of food components

- Biochemical and physiological actions

- Nutritional aspects of food

Articles relating purely to food analysis will not be published in Food \& Function - these can be published in our sister journal, Analytical Methods.

Food \& Function Full Papers must describe high impact science that will be of benefit to the community and are judged according to originality, quality of scientific content and contribution to existing knowledge. Only the most significant papers (top $25 \%$ ) will be considered for acceptance.

Good quality work, however competently researched and reported, should not be recommended for publication if it does not meet the criteria with regards to highly original and immediate interest to the broad food research community.

Authors are encouraged to provide a succinct and relevant introduction to the research and to consider the use of the Electronic Supplementary Information for additional material.

Thank you for your effort in reviewing this submission. It is only through the continued service of referees that we can maintain both the high quality of the publication and the rapid response times to authors. We would greatly appreciate if you could review this paper in $\mathbf{1 4}$ days. Please let us know if that will not be possible.

Once again, we appreciate your time in serving as a reviewer. To acknowledge this, the Royal Society of Chemistry offers a $25 \%$ discount on our books: http://pubs.rsc.org/bookshop. Please also consider submitting your next manuscript to Food \& Function.

Best wishes

Philippa Hughes

Professor Kevin Croft

Executive Editor

Editor-in-Chief 
1

\section{Food \& Function}

3

4 Antioxidant, ACE-inhibitory and antimicrobial activity of fermented goat milk: activity

5 and physicochemical properties relationship of the peptide components

6 Miriam Moreno-Montoro, ${ }^{\mathrm{a}}$ Manuel Olalla-Herrera, ${ }^{\mathrm{a}}$ José Ángel Rufián-Henares, ${ }^{\mathrm{a}}$ Rafael

7 Giménez Martínez, ${ }^{a}$ Beatriz Miralles, ${ }^{\mathrm{b}}$ Triana Bergillos, ${ }^{\mathrm{c}}$ Miguel Navarro-Alarcón ${ }^{\mathrm{a},{ }^{*}}$ \& Paula

8 Jauregi, ${ }^{\mathrm{c}}$

${ }^{a}$ Department of Nutrition and Food Science, Faculty of Pharmacy, University of Granada, Campus de Cartuja s/n, 18071, Granada, Spain

${ }^{b}$ Instituto de Investigaciones en Ciencias de la Alimentación (CIAL, CSIC-UAM, CEI-UAM + CSIC) Nicolás Cabrera 9, 28049, Madrid, Spain

${ }^{c}$ Department of Food and Nutritional Sciences, The University of Reading, Whiteknights, PO Box 226, Reading, RG6 6AP, United Kingdom 


\section{Abstract}

Increasing evidence on goat milk and their derived products health benefits beyond their nutritional value show their potential as functional foods. In this study, goat milks' fractions were tested for their total antioxidant capacity measured by different methods (ORAC, ABTS, DPPH and FRAP), as well as the angiotensin-I-converting-enzyme inhibitory and antimicrobial (against Escherichia coli and Micrococcus luteus) activities. Different whey fractions (whey; cation exchange membrane permeate, $\mathrm{P}$ and retentate, $\mathrm{R}$ ) of two fermented skimmed goat milks (ultrafiltered goat milk fermented with the classical starter bacteria or with classical starter plus the Lactobacillus plantarum $\mathrm{C} 4$ probiotic strain) were assessed. Additionally, $\mathrm{P}$ fractions were divided into two sub-fractions after passing them through a $3 \mathrm{kDa}$ cut-off membrane: (a) the permeate with peptides $<3 \mathrm{kDa}(\mathrm{P}<3)$; (b) and the retentate with peptides and proteins $>3 \mathrm{kDa}$ $(\mathrm{P}>3)$. No differences in biological activities were observed between the two fermented milks. However, the biological peptides present in the $\mathrm{P}<3$ fraction showed the highest total antioxidant capacity (for the ORAC assay) and angiotensin-I-converting-enzyme inhibitory activities. Those present in the $\mathrm{R}$ fraction showed the highest total antioxidant capacity against $\mathrm{ABTS}^{\circ+}$ and $\mathrm{DPPH}^{\circ}$ radicals. Some antimicrobial activity against $E$. coli was observed for the fermented milk with the probiotic, which could be due to some peptides released by the probiotic strain. In conclusion, small and non basic bioactive peptides could be responsible of most of angiotensin-Iconverting-enzyme inhibitory and antioxidant activities. These findings reinforce the potential benefits of the consumption of fermented goat milk in the prevention of cardiovascular diseases associated to oxidative stress and hypertension.

Keywords: goat milk, antioxidant, antimicrobial, antihypertensive, ultrafiltration, ion exchange 


\section{$43 \quad$ Introduction}

44 Fermented milks satisfy daily nutritional requirements for several nutrients and exert different health benefits. ${ }^{1}$ Furthermore, it is an important source of many bacterial strains owing to the appropriate compatibility among some of them. ${ }^{2}$ Fermented milks contain several probiotic strains, which additionally increase the already known benefits of these dairy products. Milk fermentation by classical starter bacteria (St) (Lactobacillus delbrueckii subsp. bulgaricus and Streptococcus salivarius subsp. thermophilus) changes milk properties and increases its digestibility by a decrease in lactose concentration and $\mathrm{pH}$. This process could also release biological active peptides from their inactive forms present in the corresponding sequence of the precursor protein. The specific sequence and length of released peptides depend on two main factors: (a) the precursor protein, which is different in sequence depending on the animal specie and even on the breed; ${ }^{3}$ (b) the starter bacteria, since the proteolytic system is inherent to each bacteria strain. The healthy benefits of these bioactive peptides may be attributed to their demonstrated antimicrobial, antioxidant, antihypertensive, antithrombotic, immunomodulatory and opioid activities. ${ }^{4}$ Many of the bioactive peptides have demonstrated to have multifunctional properties. Nevertheless, their specific activity depends on the amino acid composition as well as sequence. In this sense, it is well known that anionic peptides do not affect gram-negative bacteria because of repulsive electrostatic intractions between the negatively charged outer membrane and the anionic peptides. ${ }^{5}$ On the other hand, some cationic peptides have shown antimicrobial effect against gram-negative bacteria. However, not all the positively charged peptides exert antimicrobial activity and the action mechanism of milkderived antimicrobial peptides remains uncertain. ${ }^{6}$ In any case, several peptides have been discovered with antimicrobial activity that can find industrial application. ${ }^{6}$

Among the different functions of bioactive peptides, antioxidant properties are very 67 important because high levels of reactive oxygen species (ROS) and free radicals in the organism 
are associated to several diseases like cancer, diabetes, cardiovascular diseases, arthritis, allergies as well as to aging. ${ }^{7}$ In addition, ROS presence in food causes quality deterioration and shelf life reduction by lipid oxidation. ${ }^{3}$ It is known that the defense systems of organisms are often not enough to prevent oxidative damage. Some researchers have stated that antioxidant peptides present in the food system play a vital role in the maintenance of antioxidant defense systems in the organism by preventing the formation of free radicals or by scavenging free radicals and reactive oxygen species, and Cheng et al. even recommended their supplementation. ${ }^{7}$ An increasing number of food protein hydrolysates and peptides have been found to exhibit antioxidant activity, especially in peptides produced from bovine milk casein. ${ }^{3}$ In vitro measurement of antioxidant activity is key in the evaluation of the antioxidant potential of bioactive peptide-enriched preparations. Due to the complex nature of antioxidants, there is no a single technique to measure the total antioxidant capacity (TAC) of a food system. Therefore, a variety of analytical techniques are employed with this aim, which can roughly be classified into two types namely, the assays based on hydrogen atom transfer (HAT) reactions and those based on electron transfer (ET) ${ }^{8}$ Then, to study the antioxidant activity of any sample it is necessary to use at least one assay of each type in order to obtain a more complete evaluation of the TAC as the different mechanisms of antioxidant action will be taken into account; ${ }^{9}$ this is particularly important when multicomponent samples are being evaluated.

Most of biologically active peptides generated from milk proteins have demonstrated an angiotensin-I-converting enzyme-inhibitory activity (ACEi). ${ }^{10}$ This effect leads to a decrease in angiotensin II (potent vasoconstrictor) and a concomitant increase in the bradykinin level, finally yielding an overall reduction in the blood pressure. ${ }^{11}$ Although the inhibitory capacity of milk derived peptides is lower than that of chemically designed drugs, their production from natural sources could represent a healthier and more natural alternative for chronic treatment, without the side-effects associated to antihypertensive drugs. ${ }^{11}$ It is known that most publications on 
93 ACEi and antihypertensive peptides consider peptides obtained from cow milk. ${ }^{4}$ However, in 94 recent years goat milk proteins have become an important alternative source of ACEi bioactive 95 peptides. $^{12}$

96 Previous in vitro studies have demonstrated that the probiotic strain L. plantarum $\mathrm{C} 4$ has a 97 positive influence in a range of biological functions such as, mineral bioavailability, ${ }^{13}$ 98 modulation of the intestinal microbiota ${ }^{14}$ and protective and immunomodulatory capacity in a murine model of yerseniosis. ${ }^{15}$ Taking into consideration all previous findings, it was 100 hipothesised here that the probiotic strain could also enhance the antioxidant, ACE-inhibitory 101 and antimicrobial activities, in fermented goats' milks.

102 Only a few studies have focused on the bioactivity of fermented goat milk peptidic fractions. 103 Therefore, the aim of the present study was the evaluation of the biological activities 104 (antimicrobial activity against Escherichia coli and Micrococcus luteus, TAC measured by 105 ORAC, ABTS, DPPH and FRAP methods, and ACEi-activity) of two fermented skimmed goat 106 milks fermented with the classical starter bacteria [StFM] or with classical starter plus the 107 Lactobacillus plantarum $\mathrm{C} 4$ probiotic strain $[\mathrm{St}+\mathrm{LPFM}])$. The use of the probiotic strain $L$. 108 plantarum $\mathrm{C} 4$ on the milk protein concentrates produced by a local breed of goat for the 109 fermentation process was investigated here for the first time in order to produce a milk product 110 with enhanced biological activities. In addition a novel approach was followed for the 111 physicochemical characterisation (size and charge) of the peptides in the fermented milk in 112 relation to their bioactivities.

\section{Results and discussion}

\section{Total protein analysis}


116

117

As stated in Table 1 a significantly higher protein concentration was observed in whey and permeate $(\mathrm{P})$ fractions when compared to the retentate $(\mathrm{R})$, which means a large proportion of the peptides produced by the tested fermenting strains were anionic or nonionic. Additionally, the fractions of StFM have a higher protein concentration than St+LPFM; that may be due to differences in the fermentation process between St and L. plantarum C4, in particular $\mathrm{pH}$, as a lower $\mathrm{pH}$ was recorded for the fermentation with the probiotic $(4.25 \pm 0.02)$ vs. StFM $(4.39 \pm$ $0.05)$ which could have led to more protein coagulation and less soluble protein/peptide. ${ }^{16}$

\section{Total antioxidant capacity}

The results obtained for TAC showed a good correlation with protein content $(p<0.001$; $\mathrm{r}$ : ORAC $=0.772$, ABTS $=0.906$ and $\mathrm{FRAP}=0.950$ ), which could be attributed to the activity of peptides present in those fractions. In order to find which of the fractions had the most active peptides the results were also expressed as $\mu$ mol Trolox equivalents mg of $\operatorname{protein}^{-1}$ (Fig. 1). The most active fractions were different to those identified when expressed as Trolox equivalents $\mathrm{mL}^{-1}$, which means that not always the most active peptides were in the most active fractions.

The highest TAC of the fermented milk fractions (Fig. 1) was measured by ORAC for the $\mathrm{P}<3$ fraction (reaching $2.927 \pm 0.043 \mu \mathrm{mol}$ Trolox equivalents $\mathrm{mL}^{-1}$ in the $\mathrm{StFM}$ ). However, according to the other assays, the different milk fractions did not reach $0.4 \mu$ mol Trolox equivalents $\mathrm{mL}^{-1}$ (Fig. 1) for any of the fermented milks (StFM and St+LPFM). Thus, in the case of the FRAP and ABTS assays, the highest TAC was found for the whey and P fractions. Therefore these results show that fractionation by IEX did not result in increased activity as whey and P samples had similar TAC according to all methods while the retained fraction had lower activity (particularly according to ORAC and FRAP methods). On the other hand the fractionation by size (ultrafiltration) resulted in significant differences in antioxidant capacity 
(Fig. 1) with an important increase in activity. $\mathrm{P}<3 \mathrm{kDa}$ fractionation showed higher values according to ORAC, ABTS and DPPH methods, while no significant differences were observed between these fractions in FRAP assay.

The measured TAC (by ORAC and ABTS assays) for almost all analyzed fractions was significantly higher for StFM than for St+LPFM (Fig. 1). Only the samples from St+LPFM had significantly higher antioxidant capacity in whey fraction according to DPPH assay. The variation in TAC when using the different methods could be attributed to the presence of different peptides that act by different mechanisms. It has been demonstrated that the TAC of dairy products is mainly due to the activity of peptides. Some authors agreed that the main contribution to TAC comes from casein fractions in milk, suggesting that such effect is related to the self-oxidation of caseins' amino-acid residues as well as their derived peptides. Additionally, they reported that this activity cannot be replaced by free amino acids since it is the primary structure of casein itself who plays a determining role. ${ }^{17}$ Among the caseins that release antioxidant peptides, $\beta$-CN could be preferably degraded by lactic acid bacteria because it is more unstructured and accessible to cleavage, and therefore hydrolyzed to a greater extent. ${ }^{7}$ On the other hand, $\beta$-LG and lactoferrin have been reported as key components for their high scavenging activity, releasing also peptides with this activity. ${ }^{18}$ The TAC of peptides has been described as remarkably dependent on factors like molecular weight, amino acid composition and sequence. ${ }^{19}$ Many authors reported that most of milk protein-derived peptides with antioxidant activity have less than 20 amino-acid residues. ${ }^{1,7,11}$ This is in agreement with our results as the $\mathrm{P}<3$ fraction, with peptides of $\mathrm{MW}<3000$ (up to about 20 amino-acid residues), had the highest TAC (measured by ORAC), reaching more than $1 \mu \mathrm{mol}$ trolox equivalents mg $\operatorname{protein}^{-1}$ (Fig. 1). Nevertheless, Virtanen et al., ${ }^{20}$ reported the contrary, supporting higher scavenging activity against the $\mathrm{ABTS}^{-+}$radical of peptides with more than $4 \mathrm{kDa}$. However, we found that the $\mathrm{R}$ fraction contained the peptides with significantly highest TAC against ABTS ${ }^{\circ+}$ and $\mathrm{DPPH}^{\bullet}$ radicals $\left(\sim 0.4 \mu \mathrm{mol}\right.$ trolox equivalents $\mathrm{mg}$ protein ${ }^{-1} ;$ Fig. 1$)$. These findings agree 
166

167

with the results reported by other researchers, ${ }^{21}$ who stated that basic peptides had greater capacity to scavenge hydroxyl radical than weak acidic or neutral ones.

Few studies have indicated that the radical scavenging activity is strain-specific and that the higher proteolysis is not always associated with higher TAC. ${ }^{20,22}$ In our study no significant differences were observed for $\mathrm{P}<3$ fraction ( $\mu$ mol trolox equivalents $\mathrm{mL}^{-1}$ ) between $\mathrm{StFM}$ and St+LPFM, and for almost any other fraction when results were expressed as $\mu$ mol trolox equivalents $\mathrm{mg}$ of protein $^{-1}$. Therefore, the putative probiotic strain L. plantarum $\mathrm{C} 4$ by itself or by its interaction with St produced no increase in the antioxidant capacity of the fractions.

It is known that goat milk has more $\beta$-CN than cow milk. In particular, the analyzed fermented goat milks were concentrated in caseins, therefore it was expected to obtain more $\beta$ $\mathrm{CN}$ derived peptides than from cow fermented milk. Notwithstanding, results were in the range of those reported for whey fractions of cow fermented milks tested against ABTS, ranging from 0.2774 to $2.0356 \mu \mathrm{mol}$ trolox equivalents $\mathrm{mL}^{-1} .{ }^{22}$ However, the whey fraction had higher TAC than those reported for nonfermented milks $(0.489$ in UHT and $1.078 \mu$ mol trolox equivalents $\mathrm{mL}^{-1}$ in pasteurized milk). ${ }^{23}$ This finding is probably related to the proteolytic activity of the fermenting strains, which were able to release the antioxidant peptides from milk proteins. ${ }^{24}$

On the other hand, StFM and St+LPFM were produced only in $6 \mathrm{~h}$ whereas some authors reported that TAC increases with fermentation time up to $24-48$ h. ${ }^{7,22}$ Some studies reported low TAC of the whey fraction, but after fractionation by HPLC, different fractions with higher TAC were obtained..$^{22}$ Consequently, future research should focus on fractionating and identifying the peptides responsible of the TAC in the whey fraction.

Saura-Calixto and Goñi ${ }^{24}$ reported a total antioxidant daily intake in a typical Spanish diet of 3,549 $\mu \mathrm{mol}$ trolox equivalents (ABTS) and 6,014 $\mu \mathrm{mol}$ trolox equivalents (FRAP). Taking into account the whey obtained from a portion of fermented milk sample (200 g), the percentage for which this whey participate in the daily antioxidant intake is $0.75 \%$ for the ABTS and $0.50 \%$ for the FRAP methods. ${ }^{24}$ However, the total antioxidant activity of the fermented milk should be 
192 higher if we consider the precipitated fraction, with precipitated caseins and bacteria for which 193 an antioxidant activity has also been reported elsewhere. ${ }^{1}$

194 Finally, the TAC (Trolox equivalents $\mathrm{mL}^{-1}$ ) values of the fractions obtained by the different 195 methods were significantly $(p<0.001)$ correlated with each other $(r>0.830$ and $r=0.770$ for the 196 ABTS-FRAP and ORAC-FRAP, respectively). DPPH was not significantly correlated with any 197 of the other methods. However, when the TAC was expressed based on protein content a 198 significant correlation was also found for DPPH-ABTS $(\mathrm{r}=0.937$ at $p<0.001)$ and ORAC199 FRAP $(\mathrm{r}=0.807$ at $p<0.001)$. This additional significant correlation between DPPH-ABTS 200 could be explained by considering mainly the peptides/proteins responsible for the antioxidant 201 capacity. This is very interesting as there was very good correlation between methods testing 202 antioxidant capacity based on the same mechanism, as DPPH and ABTS are based on both 203 hydrogen atom transfer (HAT) and single electron transfer reactions (SET); the highest TAC was 204 found in the retentate according to the ABTS and DPPH methods. Moreover there was also good 205 correlation between methods based on different mechanisms FRAP (SET) and ORAC (HAT) but with biological relevance

207 ; the highest TAC was found in permeate according to the FRAP and ORAC methods. These 208 results demonstrate that different types of antioxidants are recovered in the different fractions with differences in their antioxidant mechanism.

\section{ACEi\% activity}

212 Firstly, the measured $\mathrm{IC}_{50}$ obtained for captopril was $0.023 \mu \mathrm{M}$, in the range reported by the manufacturer $(0.021 \pm 0.013 \mu \mathrm{M})$. This result confirms the reliability of the method used. In Fig. 2a, the ACEi activities of the different fractions of fermented goat milks expressed as percentage 215 of inhibition are shown. The whey and $\mathrm{P}<3$ fractions had the highest ACEi activity (about 50\%). Interestingly the $\mathrm{R}$ fraction did not show any activity. 
Given that in previous in vitro studies ${ }^{13-15}$ the fermentation by the probiotic strain $L$. plantarum $\mathrm{C} 4$ had led to a range of biological functions the ACEi activity was tested here. Nevertheless, no significant differences were found between StFM and St+LPFM for any of the analysed fractions. Therefore, adding the L. plantarum $\mathrm{C} 4$ probiotic strain did not significantly increase the ACEi when compared to StFM. Gonzalez-Gonzalez et al. ${ }^{27}$ found a strain of $L$. plantarum able to produce a supernatant with high ACEi activity after $24 \mathrm{~h}$ of fermentation. Regarding the other microorganisms used, L. bulgaricus has been reported as one of the most proteolytic microorganism as well as a great producer of ACEi peptides ${ }^{25}$; high ACEi activity (more than 50\%) was measured in supernatants obtained from milk fermented with 4 strains of L. bulgaricus ${ }^{26}$. As stated above for TAC, ACEi activity was significantly correlated with protein concentration $\left(\mathrm{r}^{2}=0.800 ; p<0.001\right)$. When results were expressed as ACEi\% mg protein ${ }^{1}$, the permeate fractions had the highest activity and in particular the $\mathrm{P}<3$ fraction (Fig. $2 \mathrm{~b}$ ). Therefore, as expected, smaller peptides had the highest ACEi (Fig. 2b). In that sense, the fractionation by size led to an increase in the activity. Interestingly charge had also an effect on activity $^{28}$ as the positively charged fraction of peptides (R) had very little activity (Fig. 2b). Hence the basic peptides had much less activity than the acidic (negatively charged and noncharged) peptides. This is in accordance with the results of Welderufael et al., ${ }^{28}$ who found such as IIAE with isoelectric point 4.6.

ACEi $\%$ reported values for fermented milk whey are very variable depending on the strain used. For milks fermented with L. bulgaricus and S. thermophilus, most of the reported values are around the $50 \%$, ranging from $25 \%$ to $70 \%$ of $\mathrm{ACEi} \%$ activity ${ }^{11,25}$. Some work was carried out with 13 strains at 3 different final $\mathrm{pH}$ 's and found that the maximum inhibitory activity was 
$24251 \%$ for milk fermented with Lactococcus lactis 3906 and with final $\mathrm{pH}$ 4.3. However, the milk

243 fermented with S. thermophilus did not reach the $18 \%$ of ACEi activity. ${ }^{29}$ Otte et al.

244 demonstrated a negative correlation between $\mathrm{pH}$ and ACEi activity of milk fermented with two

245 strains of L. helveticus and two species of the Lactococcus genus, reporting a range from $8 \%$ to

$24650 \%$ of ACEi activity. ${ }^{30}$ However, higher values of ACEi activity were found in milk fermented

247 with other strains like Kumis bacteria, ranging from 10.1 to $74.3 \%$ and up to $100 \%$ when

248 fermented with St plus L. acidophilus L10, L. casei L26 and B. lactis B94 ${ }^{11,31}$.

249 On the other hand, the ACEi activity has been demonstrated to be related to ionic calcium $250\left(\mathrm{Ca}^{2+}\right)$, since its concentration may activate or inhibit the $\mathrm{ACE}{ }^{27} \mathrm{We}$ demonstrated that goat 251 UFM was concentrated in caseins and that the ultrafiltration process changed $\mathrm{Ca}^{2+}$ distribution 252 [percentage of $\mathrm{Ca}$ associated to caseins changed from $63 \%$ in goat raw milk (RM) to $51 \%$ in 253 goat UFM] and $\mathrm{Ca}^{2+}$ content from $135.2 \pm 10$ to $165.6 \pm 15.1 \mathrm{mg} / 100 \mathrm{~g}$ in goat $\mathrm{RM}$ and UFM, 254 respectively. ${ }^{32}$ Additionally, the most potent antihypertensive and ACE-inhibitory peptides are 255 generated from caseinates and casein fractions. ${ }^{33}$ These findings could explain the high ACEi \% 256 found in our fermented goat milk samples. Moreover the fermentation with the probiotic $L$. 257 plantarum did not result in increased ACEi activity. One of its strains was reported to be the best $258 \gamma$-amino butyric acid (GABA) synthesizer; GABA is a non-protein derived amino acid with 259 demonstrated hypotensive effect in rats and humans. ${ }^{34}$ Future studies should focus on GABA 260 production by the probiotic L. plantarum $\mathrm{C} 4$, due to its possible relationship with the 261 hypertension control.

262

263

264

\section{Antimicrobial activity}

According to the well diffusion assay, no antimicrobial activity of the supernatants against E. coli was observed $(p>0.05)$. By contrast, in the whey and $\mathrm{P}$ fractions, E. coli grew even better than in the control assay. Nevertheless, in the spot assay for both whey and $\mathrm{P}$ fractions 
268 E.coli did not grow where the drop was placed, probably due to the low $\mathrm{pH}$ of the samples (4.33

269 and 4.59 for whey and P fractions, respectively). However, R fraction, with higher $\mathrm{pH}(6.97)$ due

270 to the presence of cationic peptides did not show any activity against $E$. coli. In relation to $M$.

271 luteus, we did not find any inhibition neither in the well diffusion assay nor in the spot test. On

272 the contrary, even higher growth was found around the well of the whey fraction compared to the

273 other fractions where no effect was shown. Additionally, the co-culture assay was carried out to

274 evaluate more precisely the possible inhibition of $E$. coli by the studied fractions. None of the

275 fractions of the fermented milk studied showed antimicrobial activity and the pathogen grew

276 almost as much as in the control (Fig. 3). However, after $24 \mathrm{~h}$ significant differences in E. coli

277 viable bacteria among control and whey and P fractions of both fermented milks (StFM and

278 St+LPFM), and R fraction of St+LPFM, were found. This inhibition could be due to the acidic

$279 \mathrm{pH}$ of whey and $\mathrm{P}$ fractions (as mentioned above). However, the $\mathrm{R}$ fraction had a $\mathrm{pH}$ more

280 similar to the control's. So in this case, the antimicrobial activity could be due to the cationic

281 peptides isolated in this fraction, such as caprine lactoferricin, which has been shown

282 antibacterial activity against $E$. coli ${ }^{35}$. Ionic charge is crucial for the attachment of peptides to the

283 bacterial membrane ${ }^{5}$; we had hypothesised that cationic peptides would have higher activity than

284 anionic or non charged peptides however, our results did not agree with this. The mechanism of

285 action of milk-derived antimicrobial peptides remains uncertain and other physicochemical

286 properties such as size amphiphilicity and conformation may play a role in their interaction with

287 bacterial membranes.

\section{Experimental}

\section{Samples}

290 Goat milk samples from the Murciano-Granadina local breed were obtained from local farms

291 (Granada province, Southeastern Spain). Specifically, every week along five weeks five batches 
292

293

294

295

296

297

298

299

300

301

302

303

304

305

306

307

308

309

310

311

312

313

314

315

316

with five samples for StFM and for St+LPFM were done, according to a previously standardised procedure. ${ }^{32}$ Each individual sample was analysed by triplicate.

\section{Sample fractionation}

Fermented milk samples were fractioned in three steps (Fig. 4). In the first step the whey fraction was obtained. All samples were centrifuged at $3000 \mathrm{~g}$ and $4{ }^{\circ} \mathrm{C}$ for $30 \mathrm{~min}$ (Sigma 2-16PK, Sartorius, Goettingen, Germany). Then, the supernatant was separated, freeze-dried and stored under refrigeration and nitrogen atmosphere until analysis. Before the fractionation, freeze-dried samples were dissolved in water up to the initial volume and then filtered through $0.22 \mu \mathrm{m}$ size pore filters Millex ${ }^{\circledR}$ - GS (Merck Millipore Ltd., Cork, Ireland) in a laminar flow cabinet and stored in sterile containers.

In the second step a cation exchange was applied. Sartobind filter MA-15 Units (Sartorius, Goettingen, Germany), with a strong acidic cation exchanger membrane. The procedure was carried out according to the operating instructions following four steps: (a) equilibration with 10 $\mathrm{mL}$ of $10 \mathrm{mM}$ potassium phosphate buffer at $\mathrm{pH} 4.5$; (b) loading with $5 \mathrm{~mL}$ of sample; (c) washing with $10 \mathrm{~mL}$ of equilibration buffer; (d) and finally elution with $5 \mathrm{~mL}$ of elution buffer (equilibration buffer $+1 \mathrm{M} \mathrm{NaCl}$ at $\mathrm{pH}$ 4.5). Then, the cation exchange units were cleaned with $0.2 \mathrm{~N} \mathrm{NaOH}$ for 30 min and equilibrated with $10 \mathrm{~mL}$ of equilibration buffer. All steps were conducted at 3 drops/s. With this method, two fractions for each sample were obtained: (1) Permeate $(\mathrm{P})$ composed by anionic or zwitterions peptides and proteins at $\mathrm{pH} 4.5$ that permeates when loading the sample; (2) and Retentate (R) composed by cationic peptides and proteins at $\mathrm{pH} 4.5$ retained in the resin and extracted in the elution step. We will refer to them as peptides because we assume that both fractions ( $\mathrm{P}$ and $\mathrm{R}$ ) could have bioactivity.

In the third step ultrafiltration was applied; molecules will be separated according to size only by a membrane with molecular weight cut off (MWCO) of $3 \mathrm{KDa}$. (Vivaspin20, Sartorius, 
317 Goettingen, Germany), The ion exchange permeates were fractionated into: (1) Permeate ( $\mathrm{P}<3$ )

318 which contained compounds sized less than $3 \mathrm{kDa}$ anionic or zwitterions peptides; (2) and 319 retentate $(\mathrm{P}>3)$ which contained compounds sized more than $3 \mathrm{kDa}$ anionic or zwitterions 320 peptides and proteins. As stated above, we will refer to them as peptides.

\section{Total soluble protein content}

The total protein content of the samples was determined based on the bicinchonic acid (BCA) assay according to the previously optimized method. ${ }^{36}$ The absorbance was measured at $562 \mathrm{~nm}$ within $10 \mathrm{~min}$ using an Ultrospec 1100 pro UV/Visible spectrophotometer (Amersham Biosciences, Little Chalfont, UK). Serial dilutions of bovine serum albumin (Sigma-Aldrich, Steinheim, Germany) were used as standard and bidistilled water as blank.

\section{Total antioxidant capacity (TAC) measured by ORAC, ABTS, DPPH and FRAP assays}

330

331

332

The $T A C$ using the oxygen radical antioxidant capacity assay $(O R A C)$ was determined according to the method described by Huang et al. ${ }^{37}$ slightly modified. In the ABTS assay, the antioxidant capacity was estimated in terms of radical scavenging activity following the procedure described by Pellegrini et al. ${ }^{38}$ In the $D P P H$ assay, the antiradical activity of different samples was estimated according to the procedure reported by Brand-Williams et al., ${ }^{39}$ which was adapted to a microplate reader. Finally for the FRAP determination the ferric reducing ability of each sample solution was estimated according to the procedure described by Benzie and $\operatorname{Strain}^{40}$ and also adapted to a microplate reader.

(1)




\section{Measurement of the ACEi\% activity}

The ACE-inhibitory activity of the samples and fractions was measured following the HPLCbased method described by Gonzalez-Gonzales et al., ${ }^{27}$ with some modifications. For this aim the determination was done by RP-UHPLC, using a Thermo Scientific Accela UHPLC system (Santa Clara, USA) with thermostated compartment sample injector at $10{ }^{\circ} \mathrm{C}$ and a $\mathrm{C} 18$ analytical column (Extrasyl-ODS2, 250 x $4.0 \mathrm{~mm}, 5 \mathrm{~mm}$, Tecknokroma, Barcelona, Spain) thermostated at $37^{\circ} \mathrm{C}$. The injection volume was $10 \mu \mathrm{L}$ and the photodiode array detector was set at $228 \mathrm{~nm}$. The flow rate was $1 \mathrm{~mL} / \mathrm{min}$ with an isocratic solution of acetonitrile $12.5 \%$ and trifluoroacetic acid $0.1 \%$ in milli-Q water over $8 \mathrm{~min}$, as it was previously reported. ${ }^{41}$

\section{Evaluation of the antimicrobial activity}

This activity was studied using two bacterial strains: a Gram-negative, Escherichia coli K-12 (E. coli), and a Gram-positive, Micrococcus luteus (M. luteus). Before the assay all samples were filtered through $0.22 \mu \mathrm{m}$ size pore filters (Millex ${ }^{\circledR}$ - GS, Merck Millipore Ltd., Cork, Ireland) under laminar flow and stored in sterile containers. Every measurement was done in triplicate and sterile Phosphate Buffered Saline (PBS, Sigma-Aldrich, Steinheim, Germany) was assayed as blank.

The antimicrobial activity of the whey, $\mathrm{P}$ and $\mathrm{R}$ fractions of StFM and St+LPFM was assayed by the well diffusion assay, based on the method described by Leon Ruiz et al. ${ }^{9}$ The antimicrobial activity was also evaluated by the spot assay of antibiosis, which was carried out according to the method described by Mohankumar and Murugalatha ${ }^{42}$ slightly modified. The agar was inoculated with the bacteria prepared as described above. Instead of doing wells, three $20 \mu \mathrm{L}$ drops of each sample were put on the agar and the plates were incubated as described above. Inhibition zones were measured from the edge of the drop. 
367

368

369

370

371

372

373

374

375

376

377

378

379

380

381

382

383

384

385

386

387

388

389

390

Finally, for the determination of the antimicrobial activity by the co-culture assay, $4.5 \mathrm{~mL}$ of broth culture (NB for E. coli and TSB for M. luteus), $0.5 \mathrm{~mL}$ of the sample and $50 \mu \mathrm{L}$ of the bacteria suspension (growth in NB or TSB at $\sim 6-8 \times 10^{8} \mathrm{cfu} \mathrm{mL}^{-1}$ ), were cultured all together. This mixture was incubated under stirring at $37^{\circ} \mathrm{C}$ for E. coli and $30^{\circ} \mathrm{C}$ for M. luteus. Aliquots at $\mathrm{t}=0,2,4,8$ and $24 \mathrm{~h}$ were taken, plated out and incubated $24 \mathrm{~h}$ at $37^{\circ} \mathrm{C}$ in NA for E.coli and 48 $72 \mathrm{~h}$ at $30^{\circ} \mathrm{C}$ in TSA for M. luteus. Finally, the colonies were counted and the mean for each plate was calculated and expressed as cfu $\mathrm{mL}^{-1}$.

\section{Statistical analysis}

The homogeneity of variances was first assessed using the Levene's test at a significance level of $5 \%(p<0.05)$. The data normal distribution was assayed with the Shapiro-Wilk test at a significance level of $5 \%(p<0.05)$. Statistical analysis of data corresponding to different fractions of the same milk type was tested using the ANOVA test when the parametric conditions were fulfilled or using the Kruskall-Wallis test for non-parametric ones. Additionally, to check the existence of statistical differences between same fractions (and whey samples) from different fermented milks (with and without the probiotic) the pair wise independent t-test was used. The evaluation of the relationship between different assays was carried out by computing the relevant correlation coefficient at the $p<0.05$ confidence level by Pearson linear correlation (for normal distribution of data) or Spearman linear correlation (for non-normal distribution of data). Analyses were performed using SPSS 17.0 program (Windows version; SPSS Inc., Chicago, IL). The significance value $p<0.05$ showed the existence of significant differences.

\section{Conclusions}


391

392

393

394

395

396

397

A remarkable TAC and high ACEi activity for both fermented goat milks (StFM and St+LPFM) were found. The whey was in general one of the most active fractions in all the assays.

However the fractionation of the whey according to size and charge gave a very good insight into the relationship between these physicochemical properties (hence chemical structure) and activity measured as antioxidant, antimicrobial and ACEi activity. Interestingly the highest TAC measured by ORAC was found in the $\mathrm{P}<3$ fraction, therefore peptides with $\mathrm{MW}<3000 \mathrm{Da}$ were the main contributors to the antioxidant activity not the proteins. On the other hand, positively charged basic peptides (those in the retentate fraction of the membrane separation step) had the highest $\mathrm{TAC}$ against $\mathrm{ABTS}^{\circ+}$ and $\mathrm{DPPH}^{\bullet}$ radicals; both methods test antioxidant mechanism according to HAT and SET mechanisms. In terms of ACEi activity, the highest activity was found in the $\mathrm{P}<3$ fraction. So the smallest (nonionic and anionic) peptides were the main contributors to the ACEi and antioxidant (according to ORAC) activities of the whey.

None of the samples had antimicrobial activity against the gram positive bacteria. The whey and the anionic/nonionic fractions of the fermented milk with the starter had some antimicrobial activity against the gram negative bacteria however, this may be partly due to the low $\mathrm{pH}$. Only the whey and the cationic fraction of the fermented milk with the probiotic showed some activity against E.coli which could be attributed to peptides released by L. plantarum C4 during the fermentation process such as those derived from lactoferrin.

Finally, the activities attributed to the whey fractions show potential health benefits of the consumption of fermented goat milk. However, further research is needed to conduct clinical trials to substantiate these and for further identification of individual peptides responsible for the activities.

\section{Acknowledgements}


416 This study was supported by the project P09-AGR-4195 from the Regional Ministry of

417 Innovation, Science and Business (Andalusia). The authors would like to thank the Spanish

418 Ministry of Education for a grant awarded to M. Moreno-Montoro (Ref. AP2009-3138) and to

419 the Spanish Ministry of Economy and Competitiveness (MINECO) for the project AGL2015-

$420 \quad 66886 \mathrm{R}$

421

422

References

4231 S. K. H. Farvin, C. P. Baron, N. S. Nielsen, J. Otte and C. Jacobsen, Food Chem., 2010, 123, 1090-1097.

4242 K. Erdmann, B. W. Y. Cheung and H. Schröder, J. Nutr. Biochem., 2008, 19, 643-54.

4253 Z. Li, a Jiang, T. Yue, J. Wang, Y. Wang and J. Su, J. Dairy Sci., 2013, 96, 4242-51.

4264 H. Korhonen, J. Funct. Foods, 2009, 1, 177-187.

4275 V. Demers-Mathieu, S. F. Gauthier, M. Britten, I. Fliss, G. Robitaille and J. Jean, Int. Dairy J., 2013,28, 94-101.

$428 \quad 6 \quad$ N. Benkerroum, Int. J. Dairy Technol., 2010, 63, 320-338.

4297 O. K. Chang, K.-H. Seol, S.-G. Jeong, M.-H. Oh, B.-Y. Park, C. Perrin and J.-S. Ham, J. Dairy Sci., $2013,96,5544-55$.

4308 D. Huang, B. Ou and R. L. Prior, J. Agric. Food Chem., 2005, 53, 1841-56.

4319 V. León-Ruiz, A. V González-Porto, N. Al-Habsi, S. Vera, M. P. San Andrés and P. Jauregi, Food Funct., 2013, 4,

$4321617-1624$

43310 D. Martínez-Maqueda, B. Miralles, I. Recio and B. Hernández-Ledesma, Food Funct., 2012, 3, 350-61.

43411 O. N. Donkor, a. Henriksson, T. K. Singh, T. Vasiljevic and N. P. Shah, Int. Dairy J., 2007, 17, $1321-1331$.

F. J. Espejo-Carpio, R. Pérez-Gálvez, E. M. Guadix and A. Guadix, J. Dairy Res., 2013, 80, 214-22.

T. Bergillos-Meca, A. Costabile, G. Walton, M. Moreno-Montoro, A. Ruiz-Bravo and M. D. Ruiz-Lopez, LWT - Food Sci Technol., 2015, 60, 420-6.

T. Bergillos-Meca, C. Cabrera-Vique, R. Artacho, M. Moreno-Montoro, M. Navarro-Alarcon, M. Olalla, R. Gimenez, I. Seiquer and M. D. Dolores Ruiz-Lopez, Food Chem., 2015, 187, 314-21. 
$447 \quad 21$

$448 \quad 22$

$449 \quad 23$

$450 \quad 24$

$451 \quad 25$

452

$453 \quad 26$

$454 \quad 27$

$455 \quad 28$

$456 \quad 29$

$457 \quad 30$

$458 \quad 31$

459

460

461

$462 \quad 33$

$463 \quad 34$

464

$465 \quad 35$

$466 \quad 36$

$467 \quad 37$

$468 \quad 38$

$469 \quad 39$

$470 \quad 40$

$471 \quad 41$

$472 \quad 42$
J. Ren, M. Zhao, J. Shi, J. Wang, Y. Jiang, C. Cui, Y. Kakuda and S. J. Xue, Food Chem., 2008, 108, 727-736.

H. S. Aloğlu and Z. Oner, J. Dairy Sci., 2011, 94, 5305-14.

A. Zulueta, A. Maurizi, A. Frígola, M. J. Esteve, R. Coli and G. Burini, Int. Dairy J., 2009, 19, 380-385.

F. Saura-Calixto and I. Goñi, Food Chem., 2006, 94, 442-447.

C. Papadimitriou, a Vafopouloumastrojiannaki, S. Silva, a Gomes, F. Malcata and E. Alichanidis, Food Chem., 2007, $105,647-656$.

H. Chen, Z. Ji, G. W. Shu and H. N. Xing, Adv. Mater. Res., 2012, 531, 442-445.

C. R. Gonzalez-Gonzalez, K. M. Tuohy and P. Jauregi, Int. Dairy J., 2011, 21, 615-622.

F. S. Welderufael, T. Gibson, L. Methven and P. Jauregi. Food Chem., 2012, 134, 1947-1958.

M. S. Nielsen, T. Martinussen, B. Flambard, K. I. Sørensen and J. Otte, Int. Dairy J., 2009, 19, 155-165.

J. Otte, T. Lenhard, B. Flambard and K. I. Sørensen, Int. Dairy J., 2011, 21, 229-238.

C. Chaves-López, A. Serio, M. Martuscelli, A. Paparella, E. Osorio-Cadavid and G. Suzzi, Food Microbiol., 2011, 28, 1041-1047.

Moreno-Montoro, M., Olalla, M., Giménez-Martínez, R., Bergillos-Meca, T., Ruiz-López, M. D., Cabrera-Vique, C., Artacho, R., \& Navarro-Alarcón, M. J.Dairy Sci,. 2015, 98, 7628-7634.

M. D. M. Contreras, R. Carrón, M. J. Montero, M. Ramos and I. Recio, Int. Dairy J., 2009, 19, 566-573.

F. Nejati, C. G. Rizzello, R. Di Cagno, M. Sheikh-Zeinoddin, A. Diviccaro, F. Minervini and M. Gobbetti, LWT - Food Sci. Technol., 2013, 51, 183-189.

I. López Expósito and I. Recio, Int. Dairy J., 2006, 16, 1294-1305.

F. Welderufael and P. Jauregi, Sep. Sci. Technol., 2010, 45, 2226-2234.

D. Huang, B. Ou, M. Hampsch-Woodill, J. A. Flanagan and Ro. L. Prior, J Agric Food Chem, 2002, 50, 4437-4444.

A. Pellegrini, C. Dettling, U. Thomas and P. Hunziker, Biochim. Biophys. Acta, 2001, 1526, 131-140.

W. Brand-Williams, M. E. Cuvelier and C. Berset, LWT - Food Sci Technol, 1995, 28, 25-30.

I. F. F. Benzie and J. J. Strain, Anal Biochem, 1996, 239, 70-76.

C. Gonzalez-Gonzalez, T. Gibson and P. Jauregi, Int. J. Food Microbiol., 2013, 167, 131-7.

A. Mohankumar and N. Murugalatha, Int. J. Biol., 2011, 3, 128-143.

473

474

475

476 
Table 1. Total protein content in the different fractions of goat fermented 478 milks (mean $\pm \mathrm{SD}, \mathrm{mg} \mathrm{mL}^{-1}$ )

\begin{tabular}{lcccccc}
\hline $\begin{array}{c}\text { Sample } \\
\text { type }\end{array}$ & $n$ & Whey fraction & P fraction & R fraction & $\begin{array}{c}\mathrm{P}<3 \mathrm{KDa} \\
\text { fraction }\end{array}$ & $\begin{array}{c}\mathrm{P}>3 \mathrm{KDa} \\
\text { fraction }\end{array}$ \\
\hline StFM & 25 & $6.78 \pm 0.773^{*}$ & $5.69 \pm 0.548^{\#}$ & $0.436 \pm 0.096$ & $2.23 \pm 0.145$ & $1.31 \pm 0.377$ \\
St+LPFM & 25 & $5.70 \pm 0.661^{*}$ & $4.30 \pm 0.843^{\#}$ & $0.355 \pm 0.055$ & $2.08 \pm 0.127$ & $0.97 \pm 0.142$ \\
$\begin{array}{l}\text { Mean } \\
\text { value }\end{array}$ & 50 & $6.16 \pm 0.868^{\mathrm{a}, *}$ & $4.85 \pm 0.990^{\mathrm{b}, \#}$ & $0.388 \pm 0.076^{\mathrm{c}, * *}$ & $2.14 \pm 0.143^{\mathrm{d}, \#}$ & $1.19 \pm 0.225^{\mathrm{e},++}$ \\
\hline
\end{tabular}

StFM: Fermented milk manufactured with skimmed milk concentrated by ultrafiltration (UFM) and fermented with the classical starter bacteria (St: L. bulgaricus and S. thermophilus); St+LPFM: Probiotic fermented goat milk manufactured with UFM and fermented with St and L. plantarum C4; Whey fraction: Fermented milk supernatant after centrifugation; P fraction: IEX (Ion exchange) permeate; R fraction: IEX retentate; $\mathrm{P}<3$ fraction: $\mathrm{P}$ fraction with less than $3 \mathrm{kDa}$ molecular weight; $\mathrm{P}>3 \mathrm{kDa}$ fraction: $\mathrm{P}$ fraction with more than $3 \mathrm{kDa}$ molecular weight.

*, ${ }^{*}$ Statistical differences between the same fractions of StFM and St+LPFM: $p<0.05$.

a,b,c,d,e, Superscripts with different letters indicate the existence of statistical differences among different fractions: $* p<0.01$; **,\#,+†p $<0.001)$. 
Table 2. Final pH of the co-culture supernatants at $24 \mathrm{~h}$ for fermented goat milks (StFM and $\mathrm{St}+\mathrm{LPFM}$ ) and control

\begin{tabular}{lccccc}
\hline Sample & $n$ & Whey fraction & P fraction & R fraction & Control \\
\hline StFM (TSB) & 25 & $5.04 \pm 0.07$ & $5.06 \pm 0.01$ & $7.46 \pm 0.07$ & $7.30 \pm 0.18$ \\
St+LPFM (NB) & 25 & $4.91 \pm 0.07$ & $4.83 \pm 0.01$ & $6.64 \pm 0.01$ & $6.85 \pm 0.12$ \\
\hline
\end{tabular}

The $\mathrm{pH}$ was measured in the supernatant of the culture media mixed with the fractions after the assay. TSB: Tryptone soy broth culture media; NB: Nutrition broth culture media; WHEY: Fermented milk supernatant after centrifugation; P: IEX (Ion exchange) permeate; R: IEX retentate; Control: Sterile PBS. 
ORAC

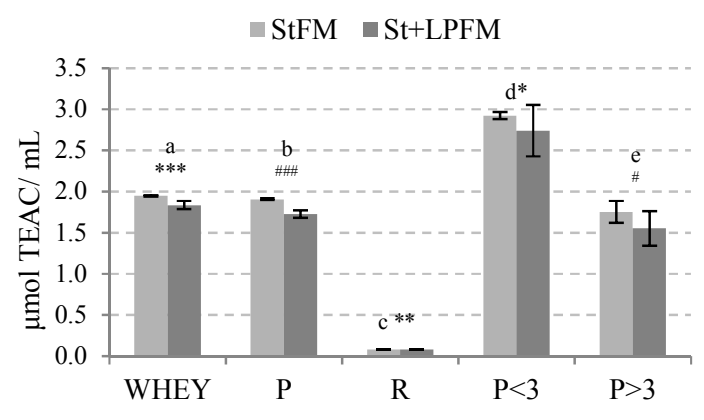

(1)

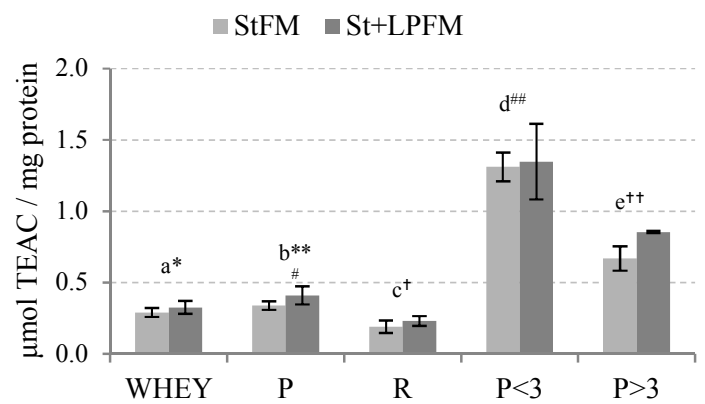

ABTS
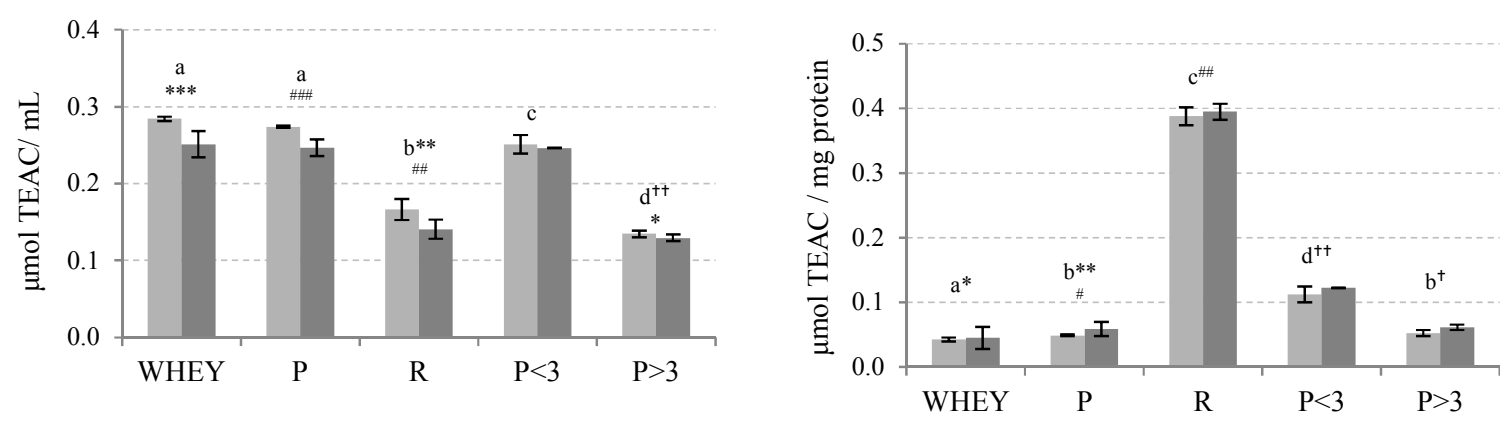

DPPH
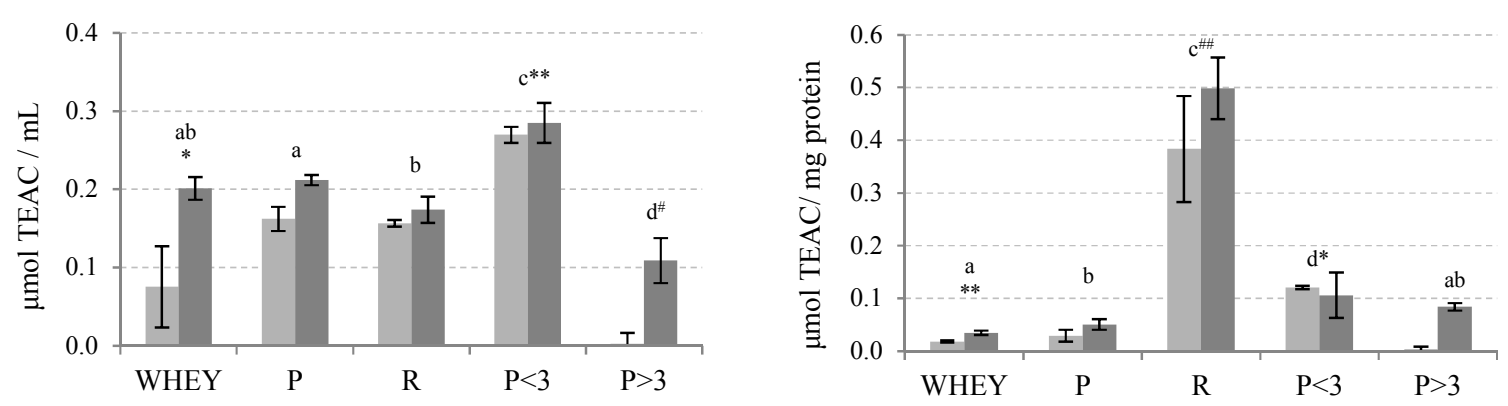

FRAP
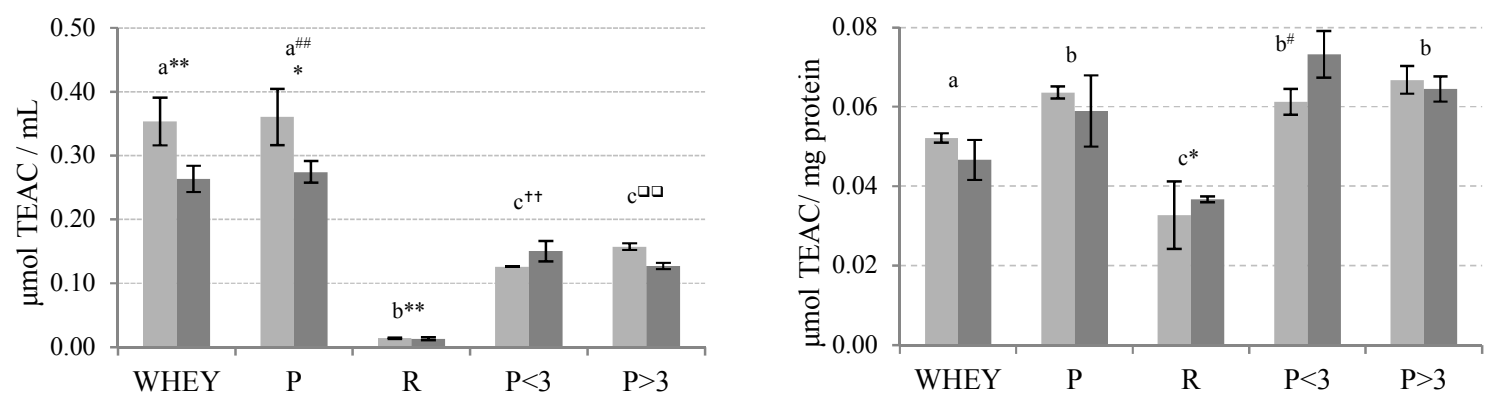

Fig. 1. Antioxidant activity (TEAC $\mathrm{mL}^{-1}$ and TEAC mg protein ${ }^{-1}$ ) of the fermented milk fractions by ORAC, ABTS, DPPH and FRAP assays

StFM: Fermented goat milk manufactured with skimmed goat milk concentrated by ultrafiltration (UFM) and fermented with the classical starter bacteria (St) L. bulgaricus and S. thermophilus; St+LPFM: Probiotic fermented goat milk manufactured with UFM and fermented St and L. plantarum C4; Whey fraction: Fermented milk supernatant after centrifugation; P fraction: IEX (Ion exchange) permeate; R fraction: IEX retentate; $\mathrm{P}<3$ fraction: $\mathrm{P}$ fraction with less than $3 \mathrm{kDa}$ molecular weight; $\mathrm{P}>3$ fraction: $\mathrm{P}$ fraction with more than $3 \mathrm{kDa}$ molecular weight.

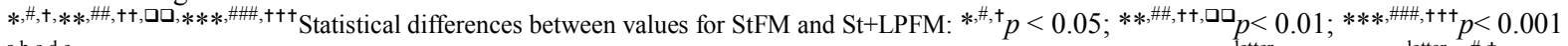
${ }^{\mathrm{a}, \mathrm{b}, \mathrm{c}, \mathrm{d}, \mathrm{e}}$ Superscripts with different letters indicate the existence of significant differences among fractions $\left({ }^{\text {letter }}: p<0.05 ;{ }^{\text {letter, }, *, \#,+}: p<0.01\right.$; 482

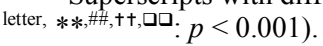




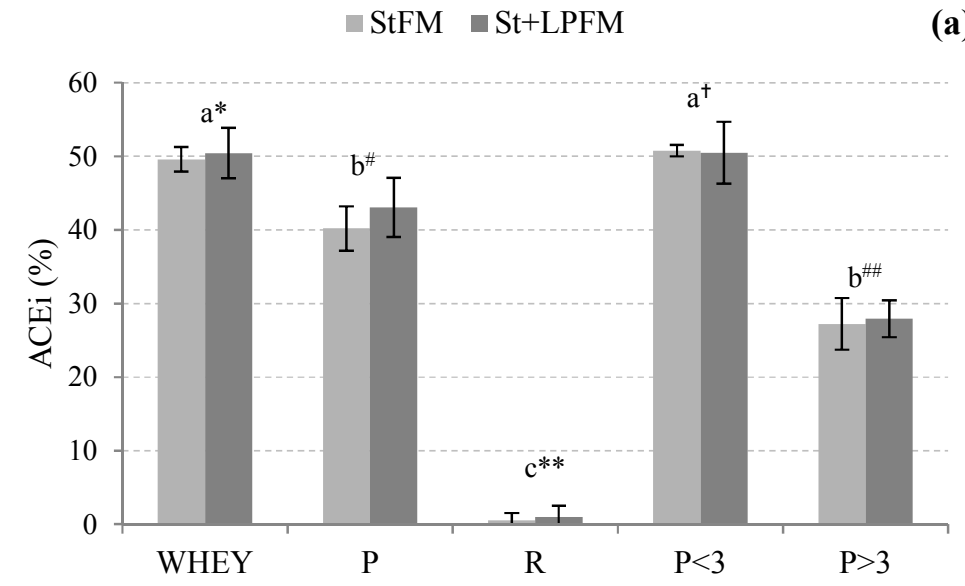

(b)

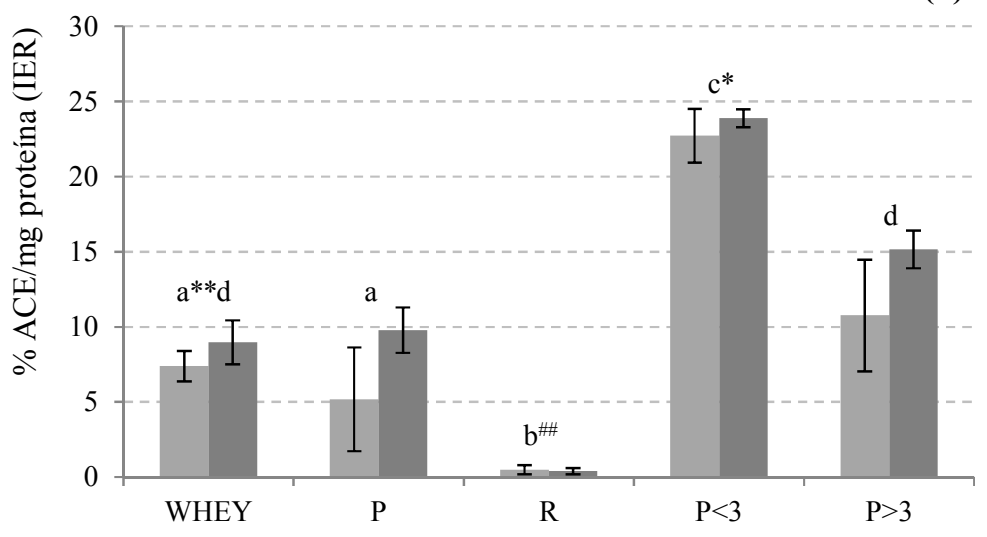

Fig. 2. Angiogensin-I-converting-enzyme inhibitory activity (ACEi) of StFM and St+LPFM expressed as percentage of ACE inhibition (a) and inhibitory efficiency ratio (IER; b).

StFM: Fermented goat milk manufactured with skimmed goat milk concentrated by ultrafiltration (UFM) and fermented with the classical starter bacteria (St) L. bulgaricus and S. thermophilus; St+LPFM: Probiotic fermented goat milk manufactured with UFM and fermented St and L. plantarum C4; Whey fraction: Fermented milk supernatant after centrifugation; P fraction: IEX (Ion exchange) permeate; $\mathrm{R}$ fraction: IEX retentate; $\mathrm{P}<3$ fraction: $\mathrm{P}$ fraction with less than $3 \mathrm{kDa}$ molecular weight; $\mathrm{P}>3$ fraction: $\mathrm{P}$ fraction with more than $3 \mathrm{kDa}$ molecular weight.

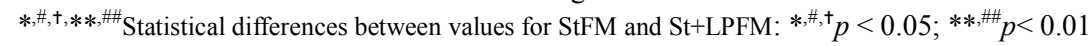

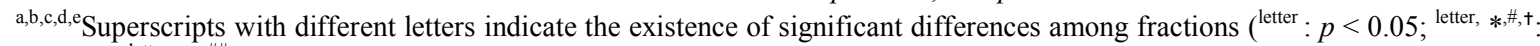

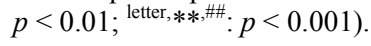




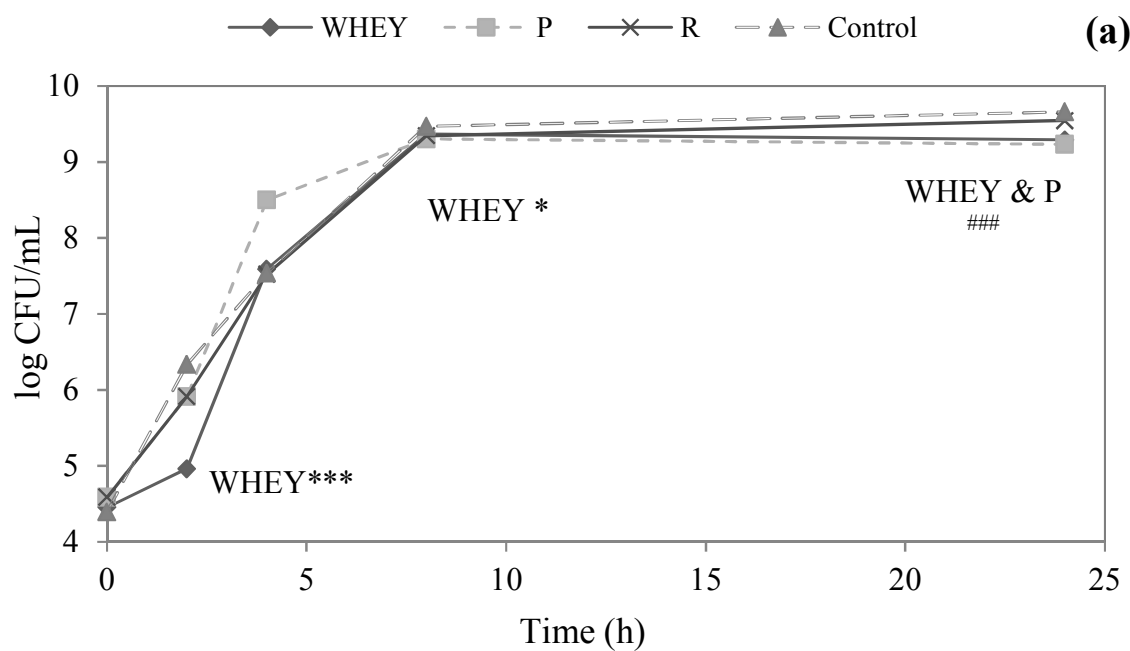

Time (h)

(b)

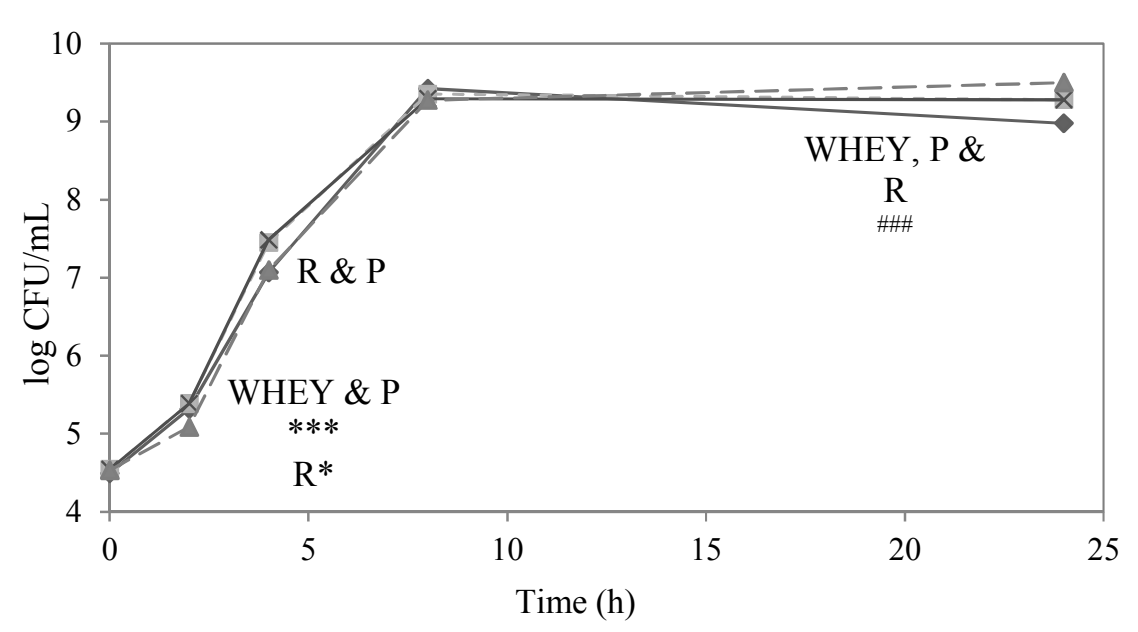

502

\footnotetext{
Fig. 3. Antimicrobial activity measured as viable $E$. coli after co-culture with the different fractions from StFM (a) and St+LPFM (b)

StFM: Fermented goat milk manufactured with skimmed goat milk concentrated by ultrafiltration (UFM) and fermented with the classical starter bacteria (St) L. bulgaricus and S. thermophilus; St+LPFM: Probiotic fermented goat milk manufactured with UFM and fermented St and L. plantarum C4; Whey fraction: Fermented milk supernatant after centrifugation; P fraction: IEX (Ion exchange) permeate; $\mathrm{R}$ fraction: IEX retentate; $\mathrm{P}<3$ fraction: $\mathrm{P}$ fraction with less than $3 \mathrm{kDa}$ molecular weight; $\mathrm{P}>3$ fraction: $\mathrm{P}$ fraction with more than $3 \mathrm{kDa}$ molecular weight; Control: sterile PBS.

*****,\#\# Significant differences for viable $E$. coli at specific time among fractions of fermented goat milks and the control: ${ }^{*} p<$

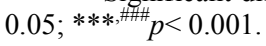
(1) 
522

523

524

525

526

527

528

529

530

531

532

533

534

535

536

537

538

539

540

541

542

543

544

545

546

547

548

549

550

551

552

553

554

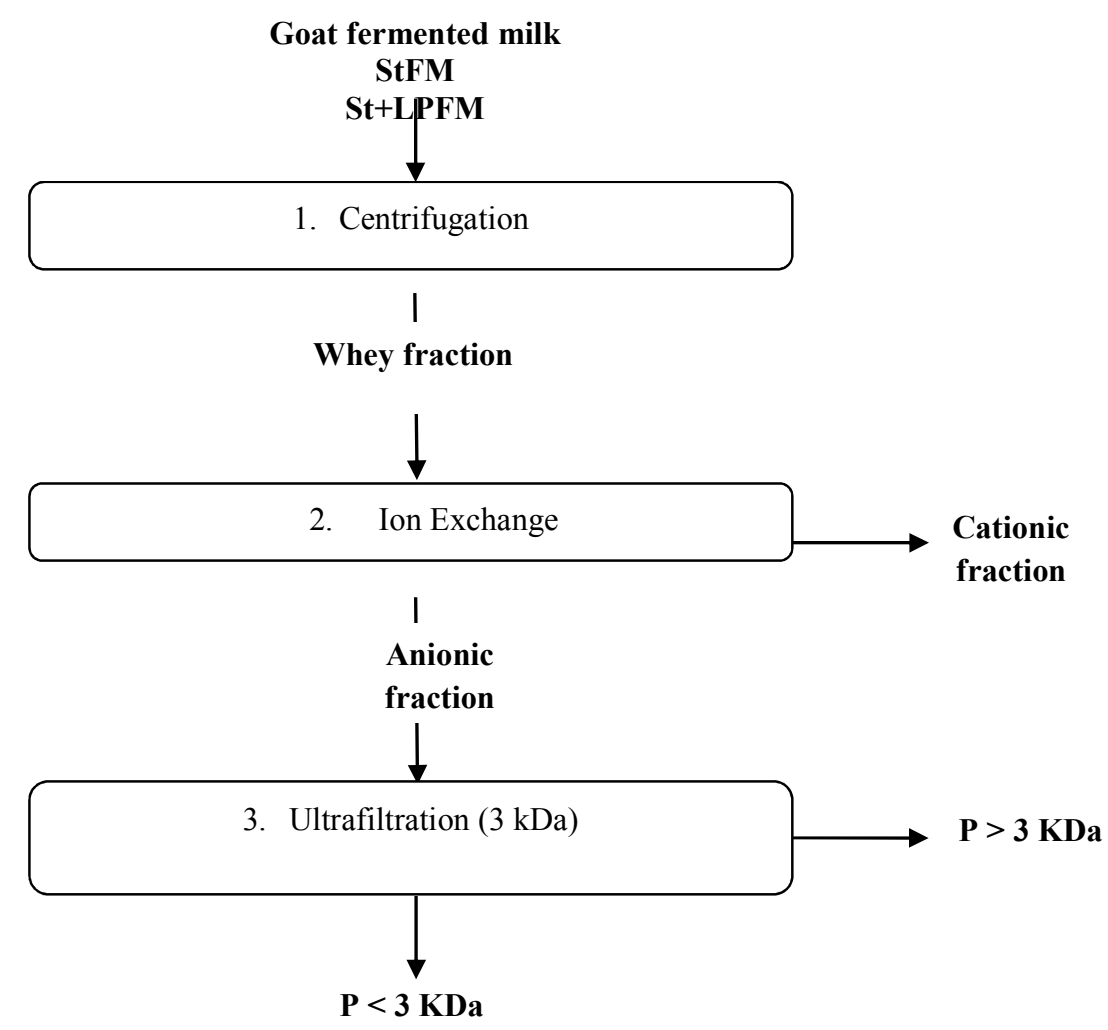

Fig. 4. Sample fractionation diagram for skimmed goat milks with classical starter bacteria (StFM) and with the classical starter St plus Lactobacillus plantarum C4 probiotic strain (St+LPFM)

Whey: Fermented milk supernatant after centrifugation; Cationic fraction: Ion exchange (IEX) permeate; Anionic fraction: IEX retentate; $\mathrm{P}<3$ fraction: $\mathrm{P}$ fraction with less than $3 \mathrm{kDa}$ molecular weight; $\mathrm{P}>3$ fraction: $\mathrm{P}$ fraction with more than $3 \mathrm{kDa}$ molecular weight. 
555

556

557

558

559

560

561 Graphical abstract

562

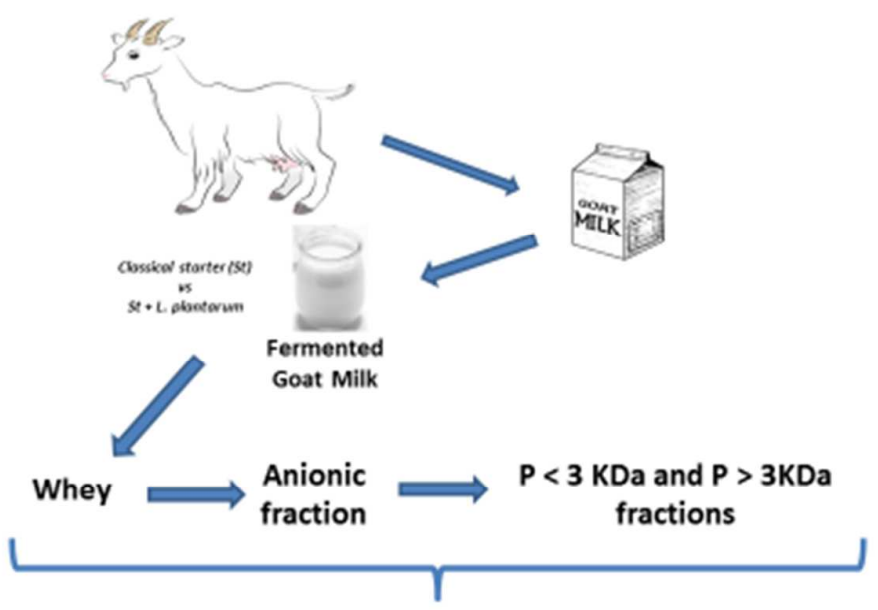

Antioxidant, antihypertensive and antimicrobial activity $\therefore \because \cdots=$
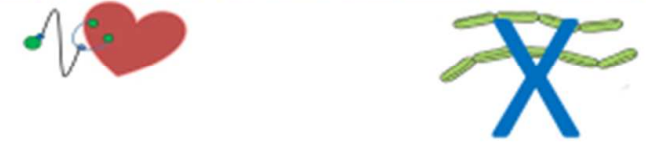


\section{Response to reviewers:}

We have taken into account the comments of both referees and we would like to thank their time and effort in making their recommendations. We proceed below to respond to each of their comments.

\section{Response to Referee: 3}

The authors have taken into account the suggestions of reviewers and editor and have produced an interesting and high quality manuscript.

Please revise the graphic abstract that does not include the

fermentation step

We have modified this

\section{Response to Referee: 4}

The focus of the work is unclear. Are we evaluating the fermented goat milk or the L. plantarum newly found in the author's laboratory.

If the fermented goat milk number of work have been done. If the $L$.

plantarum St+LPFM the work should be centered on the effects of this strain, although obviously there is no remarkable merit of the $L$.

planetarium over the fermented milk by starter strains.

We are not too clear about what the reviewer means by these comments. As commented by the reviewer 3 there is little work done on fermented goat milk and here we went even further in terms of advancing knowledge in this area by incorporating the probiotic strain. The justification of adding this strain in particular is clearly stated in lines 94-99:

'Previous in vitro studies have demonstrated that the probiotic strain L. plantarum $\mathrm{C} 4$ has a positive influence in a range of biological functions such as, mineral bioavailability, ${ }^{13}$ modulation of the intestinal microbiota ${ }^{14}$ and protective and immunomodulatory capacity in a murine model of yerseniosis. ${ }^{15}$ Taking into consideration all previous findings, it was hipothesised here that the probiotic strain could also enhance the antioxidant, ACE-inhibitory and antimicrobial activities, in fermented goats' milks'

Antimicrobial part should be removed from the manuscript. The data in Fig.3, show no or very weak antimicrobial activity against E. coli. While antimicrobial activity against $M$. lutes is not shown.

We agree with the reviewers that no antimicrobial activity is shown and we have modified this section slightly to make this more clear. However we believe that it is important to show also these negative results as in research not only the positive results are valuable.

Page 17 line 405, what is HAT and SET mechanisms?

These were defined twice in the manuscript, in lines 80-81 and in 198-99 as:

hydrogen atom transfer (HAT) and single electron transfer reactions (SET); ...' 